\title{
Fragmentation of Negative Ions from Carbohydrates: Part 1. Use of Nitrate and Other Anionic Adducts for the Production of Negative Ion Electrospray Spectra from $N$-linked Carbohydrates
}

\author{
David J. Harvey \\ Department of Biochemistry, Glycobiology Institute, University of Oxford, Oxford, United Kingdom
}

\begin{abstract}
Negative ion spectra of $\mathrm{N}$-linked glycans were produced by electrospray from a dilute solution of the glycans and various salts in methanol:water using a Waters-Micromass Q-TOF Ultima Global tandem quadrupole/time-of-flight (Q-TOF) mass spectrometer. Stable anionic adducts were formed with chloride, bromide, iodide, nitrate, sulphate, and phosphate. Unstable adducts that fragmented by a cross-ring cleavage of the reducing $\mathrm{N}$-acetylglucosamine (GlcNAc) residue, were formed with fluoride, nitride, sulphide, carbonate, bicarbonate, hydroxide, and acetate. Nitrate adducts prepared from ammonium nitrate produced the most satisfactory spectra as they were relatively free from in-source fragmentation products and gave signals that were about ten times as strong as those from corresponding $[\mathrm{M}-\mathrm{H}]^{-}$ions prepared from solutions containing ammonium hydroxide. Detection limits were in the region of $20 \mathrm{fmol}$. Neutral glycans gave both singly- and doubly-charged ions with the larger glycans preferring the formation of doubly-charged ions. Acidic glycans with several acidic groups gave ions in higher charge states as the result of ionization of the anionic groups. Low energy collision-induced decomposition (CID) spectra of the singly-charged ions were dominated by cross-ring and C-type fragments, unlike the corresponding spectra of the positive ions that contained mainly B- and Y-type glycosidic fragments. Formation of these ions could be rationalized by proton abstraction from various hydroxy groups by an initially-formed anionic adduct. Prominent glycosidic and cross-ring cleavage ions defined structural features such as the specific composition of each of the two antennae, presence of a bisecting GlcNAc residue and location of fucose residues, details that were difficult to determine by conventional techniques. Acidic glycans fragmented differently on account of charge localization on the acid functions rather than the hydroxy groups. (J Am Soc Mass Spectrom 2005, 16, 622-630) () 2005 American Society for Mass Spectrometry
\end{abstract}

$\mathrm{T}$ The function and physico-chemical properties of many proteins are modified by post-translational events of which glycosylation is among the most important [1,2]. However, because of the complexity of glycan structures, their characterization has not yet achieved the sophistication of the structural determination of the protein moiety whose primary structure consists only of a linear chain of a limited number of amino acids. Carbohydrates, on the other hand, are usually branched structures with individual monosaccharide constituents able to link together at different positions. Structural determination of $N$-linked glycans (those attached to asparagine in glycoproteins) has classically been performed by exoglycosidase digestion,

Published online March 9, 2005

Address reprint requests to Dr. D. J. Harvey, Department of Biochemistry, Glycobiology Institute, University of Oxford, South Parks Road, Oxford OX1 3QU, United Kingdom. E-mail: dh@glycob.ox.ac.uk with products monitored by techniques such as gel filtration chromatography [3] or, more recently, highperformance liquid chromatography (HPLC) [4-6] or matrix-assisted laser desorption/ionization (MALDI) mass spectrometry $[7,8]$. Knowledge of the enzyme's specificity and the number of monosaccharide units removed during incubation with the glycan leads directly to the determination of both the nature of the monosaccharides removed and their linkage.

Although use of exoglycosidase digestion is still widespread and now applicable to many $O$-linked structures [9], mass spectral fragmentation is becoming more generally used as instruments are now available that can produce high quality MS/MS spectra from small amounts of material. Fast-atom bombardment (FAB) mass spectrometry has been used in this context for many years [10-13] but its requirement for derivatization, usually by permethylation, and the presence of a high background from the matrix causes problems for analysis of the 
minuscule sample amounts now being presented for analysis in many laboratories. Consequently, most investigators now use electrospray or MALDI ionization for this work where background ion currents are lower and derivatization is not a prerequisite.

MALDI ionization produces predominantly [M+ $\mathrm{Na}^{+}$ions [14-16] that, under low energy conditions, fragment mainly by glycosidic cleavages (between the sugar rings) with smaller amounts of ions produced by cross-ring cleavages [17]; these latter ions are essential for the determination of the linkage between the sugar rings. Recording of the fragment ions from MALDIgenerated ions was initially restricted to post-source decay (PSD) technology [18] but can now be achieved much more satisfactorily by CID on Q-TOF [19-22] or ion-trap instruments.

Electrospray ionization produces several types of ion from carbohydrates, depending on the ion source conditions and additives to the solvent. $[\mathrm{M}+\mathrm{Na}]^{+}$Ions can be obtained, as in MALDI, and reach their highest abundance at high cone voltages [23]. However, they are usually accompanied by a considerable amount of in-source fragmentation. Sensitivity generally falls as a function of increasing mass such that it is difficult to record $[\mathrm{M}+\mathrm{Na}]^{+}$ions from the larger glycans. Nevertheless, both the $[\mathrm{M}+\mathrm{Na}]^{+}$ions from underivatized and derivatized glycans and ions formed by adduction with other metals provide informative spectra containing both glycosidic and cross-ring fragments [22-28]. Both $[\mathrm{M}+\mathrm{H}]^{+}$and doubly-charged ions produced by protonation are formed under milder ion-source conditions but their MS/MS spectra are comparatively simple and do not generally contain ions produced by cross-ring cleavages.

Fragmentation of negative ions has received less attention but it would appear that fragmentation of those from neutral glycans differs considerably from that of positive ions. Several studies on neutral glycans from human urine [29] and milk [30-32], acidic glycans from oranges [33], recombinant human erythropoietin [34], and various sialylated glycans [35] have shown that fragmentation of negative ions produces prominent C-type glycosidic cleavages (Domon and Costello nomenclature [36]) and A-type cross-ring cleavages rather than the B- and Y-type glycosidic cleavages that are common to the fragmentation of positive ions. Little work has been published on the fragmentation of negative ions formed from $N$-linked glycans [35] and, consequently, in this work, we demonstrate its usefulness in producing abundant cross ring fragmentation products that can be used to define several of the structural features of these compounds that are difficult to identify by traditional techniques. Unfortunately, $[\mathrm{M}-\mathrm{H}]^{-}$ions tend to be rather unstable and produce abundant in-source fragment ions. In particular, the $N$-linked glycans produce an abundant ${ }^{2,4} \mathrm{~A}$ fragment from the reducing-terminal GlcNAc residue involving loss of 161 mass units, very close to, and easily confused with, the 162 difference (hexose residue) separating many glycans in a typical mixture. Consequently, glycans were stabilized by adduction with various anions. This paper concentrates on optimum conditions for ion formation and the accompanying papers [37, 38] discuss detailed fragmentation mechanisms for formation of the diagnostic ions.

\section{Materials and Methods}

\section{Materials}

$N$-linked glycans were released by large scale hydrazinolysis followed by reacetylation [39, 40] from the well-characterized glycoproteins (Sigma Chemical Co. Ltd., Poole, Dorset, UK) ribonuclease B [41], porcine thyroglobulin [42, 43], chicken ovalbumin [44, 45], and bovine fetuin [46]. Methanol was obtained from BDH Ltd. (Poole, UK) and the various inorganic salts were from Aldrich Chemical Co. Ltd. (Poole, UK) and BDH. 2,5-dihydroxybenzoic acid (DHB) was from Aldrich. Water was distilled before use.

\section{Electrospray Mass Spectrometry}

Electrospray mass spectrometry was performed with a Waters-Micromass quadrupole-time-of-flight (Q-TOF) Ultima Global instrument (Waters/Micromass Ltd, Simonsway, Manchester, UK). Samples (about 50 $\mathrm{pmol} / \mu \mathrm{L}$ ) in 1:1 (vol:vol) methanol:water containing 0.1 $\mathrm{M}$ ammonium hydroxide, or one of the salts listed in Table $1,{ }^{\circ}$ were ${ }^{\circ}$ infused ${ }^{\circ}$ at $^{\circ} 5^{\circ} \mu \mathrm{L} / \mathrm{min}^{\circ}$ The $^{\circ}$ ion ${ }^{\circ}$ source ${ }^{\circ}$ was maintained at $120^{\circ} \mathrm{C}$, the nebulizer gas at $100^{\circ} \mathrm{C}$ and the cone and desolvation nitrogen flows were 50 and $450 \mathrm{~L} / \mathrm{h}$, respectively. The infusion needle potential was $3.0 \mathrm{kV}$, the cone was at $100 \mathrm{~V}$ and the RF-1 voltage, which has an effect similar to that of the cone on older instruments, was set at 180 and $80 \mathrm{~V}$ for singly- and

Table 1. Highest mass ion produced by negative ion electrospray by $N$-linked glycans in the presence of various anions

\begin{tabular}{lcl}
\hline Anion & Adduct mass & lons of highest mass \\
\hline \hline $\mathrm{F}^{-}$ & 19 & {$[\mathrm{M}-161]^{-}$} \\
$\mathrm{Cl}^{-}$ & 35 & {$[\mathrm{M}+\mathrm{Cl}]^{-}$} \\
$\mathrm{Br}$ & 79 & {$[\mathrm{M}+\mathrm{Br}]^{-}$} \\
$\mathrm{I}^{-}$ & 127 & {$[\mathrm{M}+\mathrm{I}]^{-}$} \\
$\mathrm{OH}^{-}$ & 17 & {$[\mathrm{M}-\mathrm{H}]^{-}$} \\
& & {$[\mathrm{M}-161]^{-}$} \\
$\mathrm{OAc}^{-}$ & 59 & {$[\mathrm{M}-161]^{-}$} \\
$\mathrm{HCO}_{3}^{-}$ & 61 & {$[\mathrm{M}-161]^{-}$} \\
$\mathrm{CO}_{3}^{2-}$ & 60 & {$[\mathrm{M}-161]^{-}$} \\
$\mathrm{NO}_{3}^{-}$ & 62 & {$\left[\mathrm{M}+\mathrm{NO}_{3}\right]^{-}$} \\
$\mathrm{NO}_{2}^{-}$ & 46 & {$[\mathrm{M}-161]^{-}$} \\
$\mathrm{H}_{2} \mathrm{PO}_{4}^{-}$ & 97 & {$\left[\mathrm{M}+\mathrm{H}_{2} \mathrm{PO}_{4}\right]^{-}$} \\
$\mathrm{SO}_{4}^{2-}$ & 97 & {$\left[\mathrm{M}+\mathrm{HSO}_{4}\right]^{-}$} \\
$\mathrm{SO}_{3}^{-}$ & 80 & {$[\mathrm{M}-161]^{-}$} \\
$\mathrm{S}_{2} \mathrm{O}_{3}^{-}$ & 112 & {$\left[\mathrm{M}+\mathrm{S}_{2} \mathrm{O}_{3}\right]^{-}$} \\
$\mathrm{MnO}_{4}^{-}$ & & {$[\mathrm{M}-161]^{-}$} \\
$\mathrm{Cr}_{2} \mathrm{O}_{7}^{2-}$ & 119 & {$[\mathrm{M}-161]^{-}$} \\
\hline
\end{tabular}


doubly-charged ions, respectively. Its effect on ion formation was recorded over the range $0-250 \mathrm{~V}$ and the results ${ }^{\circ}$ reported ${ }^{\circ}{ }^{\circ}{ }^{\circ}$ Figure $^{\circ} 2^{\circ}$ (below). ${ }^{\circ}$ Spectra ${ }^{\circ}\left(2^{\circ}{ }^{\circ}\right.$ scans) were acquired with a digitization rate of $4 \mathrm{GHz}$ and accumulated until a satisfactory signal:noise ratio had been obtained (noise level less than about 1\%). For MS/MS data acquisition, the parent ion was selected at low resolution (about $5 \mathrm{~m} / \mathrm{z}$ mass window) to allow transmission of isotope peaks and fragmented with argon at a pressure (recorded on the instrument's pressure gauge) of 0.5 Bar. The voltage on the collision cell was adjusted with mass and charge to give an even distribution of fragment ions across the mass scale, i.e., the fragments were not biased towards low or high mass. Typical values were $80-120 \mathrm{~V}$ for the singlycharged ions and 30-50 V for the doubly-charged ions. Other voltages were as recommended by the manufacturer. Instrument control, data acquisition, and processing were performed with a MassLynx data system (Version 4.0) running on a Pentium IV PC with the Microsoft Windows XP operating system.

\section{Sensitivity}

Ribonuclease glycans [ $1 \mathrm{mg}$, estimated to contain about $600 \mu \mathrm{g}(500 \mathrm{nM})$ of $\left.(\mathrm{GlcNAc})_{2}(\mathrm{Man})_{5}\right]$ were diluted successively by 1:5 increments with 1:1 (vol:vol) methanol:water containing $0.1 \mathrm{mM}$ ammonium hydroxide, copper nitrate or ammonium nitrate. Solutions were infused for one min. at each concentration and the total ion current was measured for the molecular ion. Five measurements were made at each concentration.

\section{MALDI Mass Spectra}

The MALDI mass spectrum of chicken egg white glycans was recorded with the above Q-TOF instrument. The sample (about $10 \mathrm{pmol}$ ) in water $(0.5 \mu \mathrm{L})$ was mixed with the matrix $(0.3 \mu \mathrm{L}$ of a saturated solution of DHB in acetonitrile) and allowed to dry under ambient conditions on the MALDI target. The sample:matrix mixture was then recrystallized from ethanol $(0.1 \mu \mathrm{L})$.

\section{Results and Discussion}

\section{Neutral Glycans-Ionization}

Although abundant negative ions were obtained when the carbohydrates were sprayed from water:methanol solutions, stronger spectra were recorded when ammonium ${ }^{\circ}$ hydroxide ${ }^{\circ}$ was $^{\circ}$ added ${ }^{\circ}$ to $^{\circ}$ the ${ }^{\circ}$ solution $^{\circ}$ (Figure ${ }^{\circ} 1$ a). However, a considerable amount of in-source fragmentation was observed, particularly at high (above about $200 \mathrm{~V})$ RF-1 potentials with the result that most observed peaks were produced by fragment ions. The RF-1 potential changes the ratio of singly- to doublycharged ions with high potentials favouring the formation of singly-charged ions. The observation of an enhanced signal in the presence of ammonium hydrox- ide suggested that the initial ionization was formation of an adduct of the type $[\mathrm{M}+\mathrm{OH}]^{-}$which then lost water to form the observed $[\mathrm{M}-\mathrm{H}]^{-}$ion. In an attempt to stabilize the initially-formed ion and reduce the amount of in-source fragmentation, the effect of anions other than $\mathrm{OH}^{-}$was investigated. These anions are listed ${ }^{\circ}{ }^{\circ}{ }^{\circ} T_{a b l e}{ }^{\circ}$. Previous ${ }^{\circ}$ investigators ${ }^{\circ}$ have ${ }^{\circ}$ noted $^{\circ}$ the ability $^{\circ}$ of $^{\circ}$ certain $^{\circ}$ anions, ${ }^{\circ}$ such $^{\circ}$ as $^{\circ}$ sulfate $^{\circ}[47-49]^{\circ}$ and chloride $\left[49^{\circ}-53\right]^{\circ}$ to $^{\circ}$ form ${ }^{\circ}$ stable ${ }^{\circ}$ adducts ${ }^{\circ}$ with $^{\circ}$ carbohydrates and to act as proton scavengers with the production of $[\mathrm{M}-\mathrm{H}]^{-}$ions following loss of the appropriate acid, such as $\mathrm{HCl}$ from a chloride adduct. The ability of the various anions to induce fragmentation was then investigated.

Negative ion spectra of $N$-linked glycans from hen $\mathrm{egg}^{\circ}{ }^{\text {white }}{ }^{\circ}$ glycoproteins, ${ }^{\circ}$ mainly ${ }^{\circ}$ ovalbumin ${ }^{\circ}[45],{ }^{\circ}$ were recorded from water:methanol (1:1, vol:vol) containing the various anions. The stability of the resulting anion complexes varied considerably. Some, such as those formed from nitrate, phosphate, sulfate and halogens other than fluoride gave abundant $\left[\mathrm{M}+\right.$ anion $^{-}$ions (Figure $\left.^{\circ} 1 \mathrm{~b}\right)^{\circ}$ whereas $^{\circ}$ others $^{\circ}$ gave $^{\circ}$ extensive $^{\circ}$ in-source fragmentation (Figure $1 \mathrm{a}$ ), sometimes ${ }^{\circ}$ with the complete decomposition of the complex. The major high-mass ion that was observed under these conditions was usually the ${ }^{2,4} \mathrm{~A}$ cross-ring cleavage product $[\mathrm{M}-\mathrm{H}-161]^{-}$ where cleavage had occurred at the reducing terminus (loss of AcNH-CH=CH-OH). Results are summarized in Table ${ }^{\circ} 1 .^{\circ}$ These $^{\circ}$ observations ${ }^{\circ}$ supported $^{\circ}$ the ${ }^{\circ}$ above ${ }^{\circ}$ conclusion that the sugars were initially ionized by anion addition in all cases and that the initial fragmentation involved loss of the corresponding acid. Detailed investigations of the mechanisms leading to the production of the various fragment ions (see accompanying papers

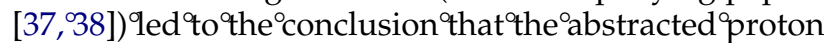
originated from one of the many hydroxyl or acid

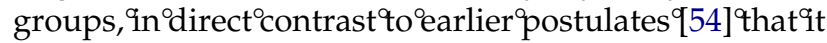
was mainly the proton from the anomeric hydroxyl group that was eliminated in the formation of $[\mathrm{M}-\mathrm{H}]^{-}$ ions. The nature of the cation appeared not to affect the formation of these negative ions although it did affect the detection limits as many of the salts used to produce the adducts tended to form salt clusters with adverse effects on the signal:noise ratio.

The monovalent anions gave the least complicated spectra and were selected for further study. Of these anions, nitrate proved to be the most useful. It formed stable $\left[\mathrm{M}+\mathrm{NO}_{3}\right]^{-}$complexes with all glycans examined although some of the smaller compounds showed a little in-source fragmentation at high RF-1 voltage. Figure $^{\circ} 2^{\circ}$ shows $^{\circ}$ that, ${ }^{\circ}$ for ${ }^{\circ}$ all ${ }^{\circ}$ nitrate ${ }^{\circ}$ adducts $^{\circ}$ produced from ovalbumin glycans, ion intensity rose as a direct function of the RF-1 voltage but that fragmentation started to reduce the intensity in a mass-related manner at the higher RF-1 potentials. The smallest carbohydrate usually encountered in mixtures of $\mathrm{N}$-glycans is that corresponding to the trimannosyl-chitobiose pentasaccharide core. The $\left[\mathrm{M}+\mathrm{NO}_{3}\right]^{-}$ions $(\mathrm{m} / \mathrm{z}$ 972.3) from this compound and all larger glycans, were stable below a 


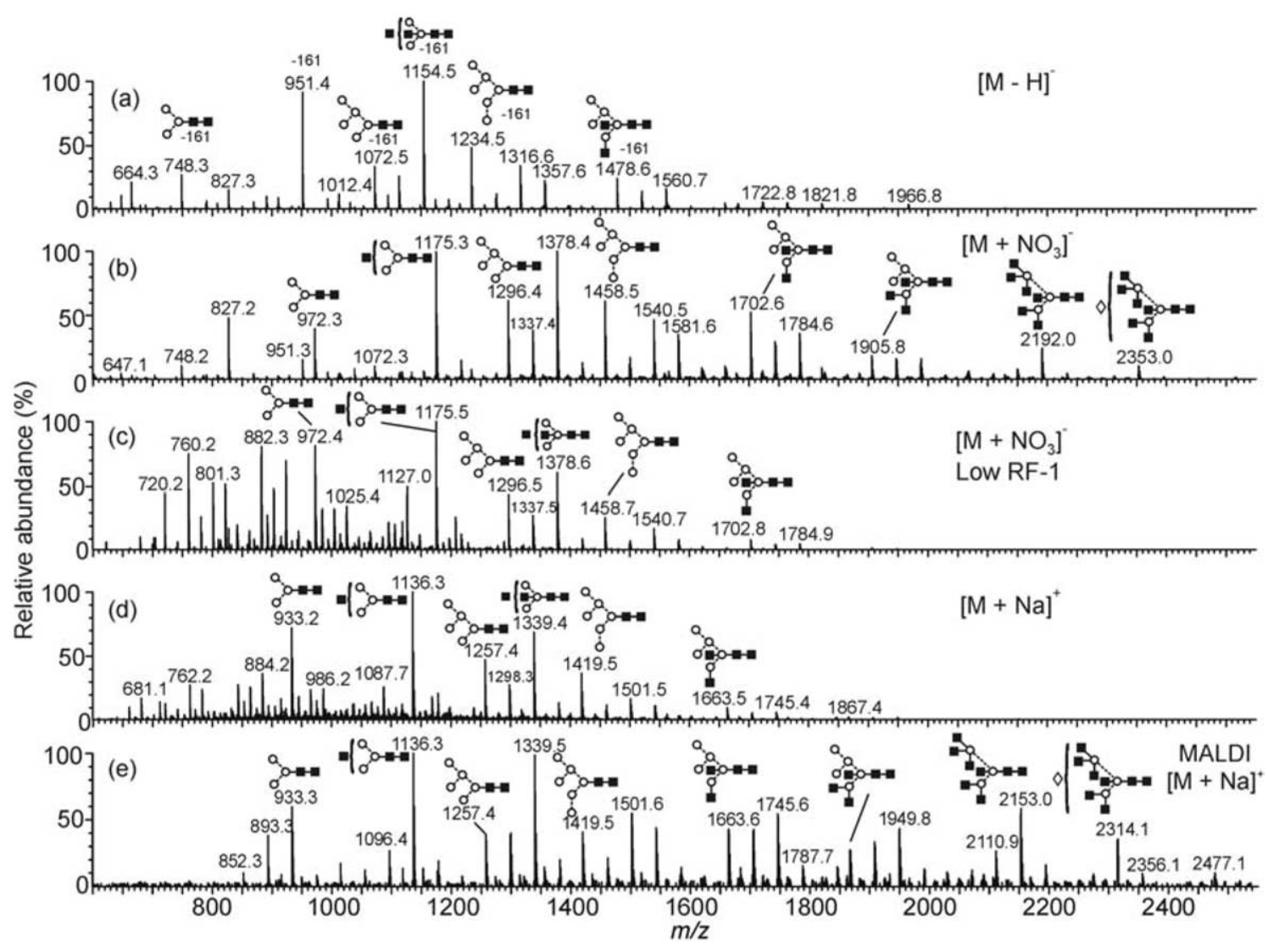

Figure 1. Mass spectra of $N$-linked glycans released from chicken egg glycoproteins. (a) Negative ion electrospray spectrum in the presence of ammonium hydroxide showing extensive ${ }^{2,4} \mathrm{~A}$-type cross-ring type in-source fragmentation from the reducing-terminal GlcNAc residue (loss of 161 mass units (AcNH-CH=CH-OH). (b) Negative ion electrospray spectrum in the presence of ammonium nitrate showing stable $\left[\mathrm{M}+\mathrm{NO}_{3}\right]^{-}$ions. (c) Negative ion electrospray spectrum in the presence of ammonium nitrate but recorded with an RF-1 potential of $80 \mathrm{~V}$ to obtain doubly-charged ions (most ions in the range $m / z$ 700-1200). (d) Positive ion electrospray spectrum $\left([\mathrm{M}+\mathrm{Na}]^{+}\right.$ions). The ions of low abundance in the $m / z 600-1200$ region are mainly fragments. (e) Positive ion MALDI spectrum of the $[\mathrm{M}+\mathrm{Na}]^{+}$ions. Key to symbols for the structural formulas: filled square $=$ GlcNAc, open circle $=$ mannose, open diamond $=$ galactose .

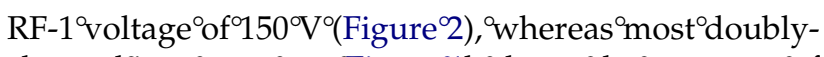

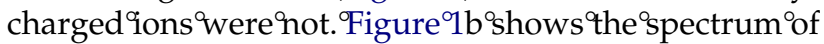
the hen egg white glycans recorded at this voltage.

Compared with the $[\mathrm{M}+\mathrm{Na}]^{+}$ions in the MALDI spectrum, where previous work has shown that glycans across this mass range all produce comparable signals $[55],{ }^{\circ}$ the ${ }^{\circ}\left[\mathrm{M}^{\circ}+{ }^{\circ} \mathrm{NO}_{3}\right]^{-}$ions from the neutral glycans showed a slight drop in sensitivity with increasing mass but to a far lesser extent than the $\left[\mathrm{M}+\mathrm{Na}^{+}\right.$ions produced $^{\circ}$ by $^{\circ}$ electrospray $^{\circ}\left(\text { Figure }^{\circ} 1 \mathrm{~d}\right)^{\circ}[23]^{\circ} .^{\circ}$ The ${ }^{\circ}$ signal strength from the larger glycans was stronger than that from any of the other adducts in either positive or negative ion modes and the spectra were less complicated, particularly compared with the MALDI spectrum (Figure $\left.^{\circ} 1 \mathrm{e}\right),{ }^{\circ}$ because ${ }^{\circ}$ of ${ }^{\circ}$ the ${ }^{\circ}$ absence ${ }^{\circ}$ of ${ }^{\circ}$ fragment ${ }^{\circ}$ ions. The $[\mathrm{M}-\mathrm{H}]^{-}$ions from the singly-charged sialylated glycans tended to be weak and were only observed for the smaller, monosialylated compounds. However, multiple sialylation gave doubly-and triply-charged ions of composition $[\mathrm{M}-2 \mathrm{H}]^{2-}$ and $[\mathrm{M}-3 \mathrm{H}]^{3-}$ respectively $^{\circ}$ in $^{\circ}$ high $^{\circ}$ abundance ${ }^{\circ}$ Figure $\left.^{\circ} 3\right)^{\circ}$ as $^{\circ}$ these compounds contained several readily ionisable protons and did not form stable nitrate adducts.

Doubly-charged ions of the type $[\mathrm{M}+2 \mathrm{X}]^{2-}$ were

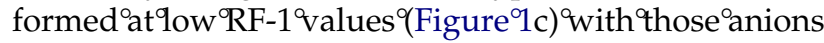
that gave stable $[\mathrm{M}+\mathrm{X}]^{-}$ions. Again nitrate gave the strongest doubly-charged ions but failed to produce these ions from glycans with masses below about 1500 . Above this mass, however, the abundance of the doubly-charged ions rose rapidly with mass such that there was better detection of the larger glycans than with the singly-charged ions. $\left.{ }^{9} \mathrm{M}^{\circ}+2 \mathrm{X}\right]^{2-}$ ions ${ }^{\circ}$ formed ${ }^{\circ}$ with ${ }^{\circ}$ other anions showed similar behavior.

The limit of detection of the $\left[\mathrm{M}+\mathrm{NO}_{3}\right]^{-}$ions was measured with a series of serial dilutions with the highmannose glycan (Man $)_{5}(\mathrm{GlcNAc})_{2}$ together with the detection limit produced by the $[\mathrm{M}-\mathrm{H}]^{-}$ion generated from an ammonium-hydroxide-containing solution and from the $\left[\mathrm{M}+\mathrm{NO}_{3}\right]^{-}$adducts formed from copper and ammonium $^{\circ}$ nitrates ${ }^{\circ}$ as $^{\circ}$ shown $^{\circ}$ in $^{\circ}$ Figure $^{\circ} 4 .{ }^{\circ} \mathrm{Graphs}^{\circ}$ of 


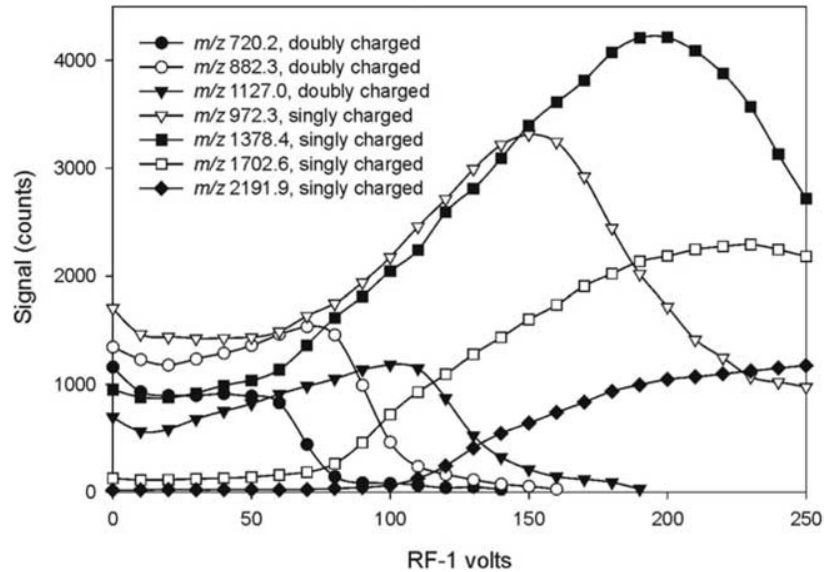

Figure 2. Plots of signal strength against RF-1 potential for selected singly and doubly-charged ions from chicken egg glycoproteins.

concentration against signal strength were linear from about $20 \mathrm{pmol} / \mu \mathrm{L}$ (100 pmol infused) to the detection limit of about $20 \mathrm{fmol}$ infused (3:1 signal:noise). Copper and potassium nitrate readily formed salt clusters such that to record the signals from the lower concentrations of glycan, the amount of nitrate added to the electrospray solution had to be reduced in order to minimise cluster formation to acceptable levels. However, these lower nitrate levels were insufficient to form complexes with the sugars which appeared in the spectra as $[\mathrm{M}-\mathrm{H}]^{-}$and fragment ions. With ammonium nitrate, however, negligible cluster formation occurred allowing the nitrate concentration to be maintained to give only $\left[\mathrm{M}+\mathrm{NO}_{3}\right]^{-}$ions.

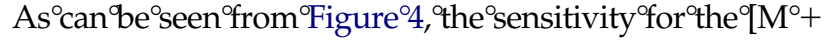
$\left.\mathrm{NO}_{3}\right]^{-}$ions formed from ammonium nitrate was about 10-fold greater than that for the $[\mathrm{M}-\mathrm{H}]^{-}$ions.

\section{Fragmentation}

The CID fragmentation spectra shown by all complexes were similar to those of the $[\mathrm{M}-\mathrm{H}]^{-}$ions but the nitrate adduct, in particular, gave particularly informative spectra as shown for the high-mannose $N$-linked glycan $(\mathrm{Man})_{5}\left(\mathrm{GlCNAc}_{2^{\circ}}\left(\right.\right.$ Figure $\left.^{\circ} 5\right)$. $^{\circ} \mathrm{The}^{\circ}$ similarity $^{\circ}$ between the spectra could best be rationalized by assuming that the first stage of fragmentation involved the elimination of the corresponding acid, such as $\mathrm{HNO}_{3}$ with the anion abstracting a proton from hydroxyl groups from various positions of the molecule. The halide adducts showed the same trends towards inducing fragmentation as the alkali metals in that the most massive adduct, from iodine, produced little fragmentation ${ }^{\circ}$ other ${ }^{\circ}$ than $^{\circ}$ the ${ }^{\circ}$ loss $^{\circ}$ of ${ }^{\circ}$ iodine ${ }^{\circ}$ (Figure $\left.{ }^{\circ} 6 \mathrm{c}\right)^{\circ}$ and ${ }^{\circ}$ that fragmentation became more extensive as the mass of the adduct decreased. The bromide and chloride adducts $^{\circ}\left(\right.$ Figure $^{\circ} 6 a^{\circ}$ and ${ }^{\circ} b,{ }^{\circ}$ respectively) ${ }^{\circ}$ gave $^{\circ}$ good $^{\circ}$ fragmentation spectra but the presence of two abundant

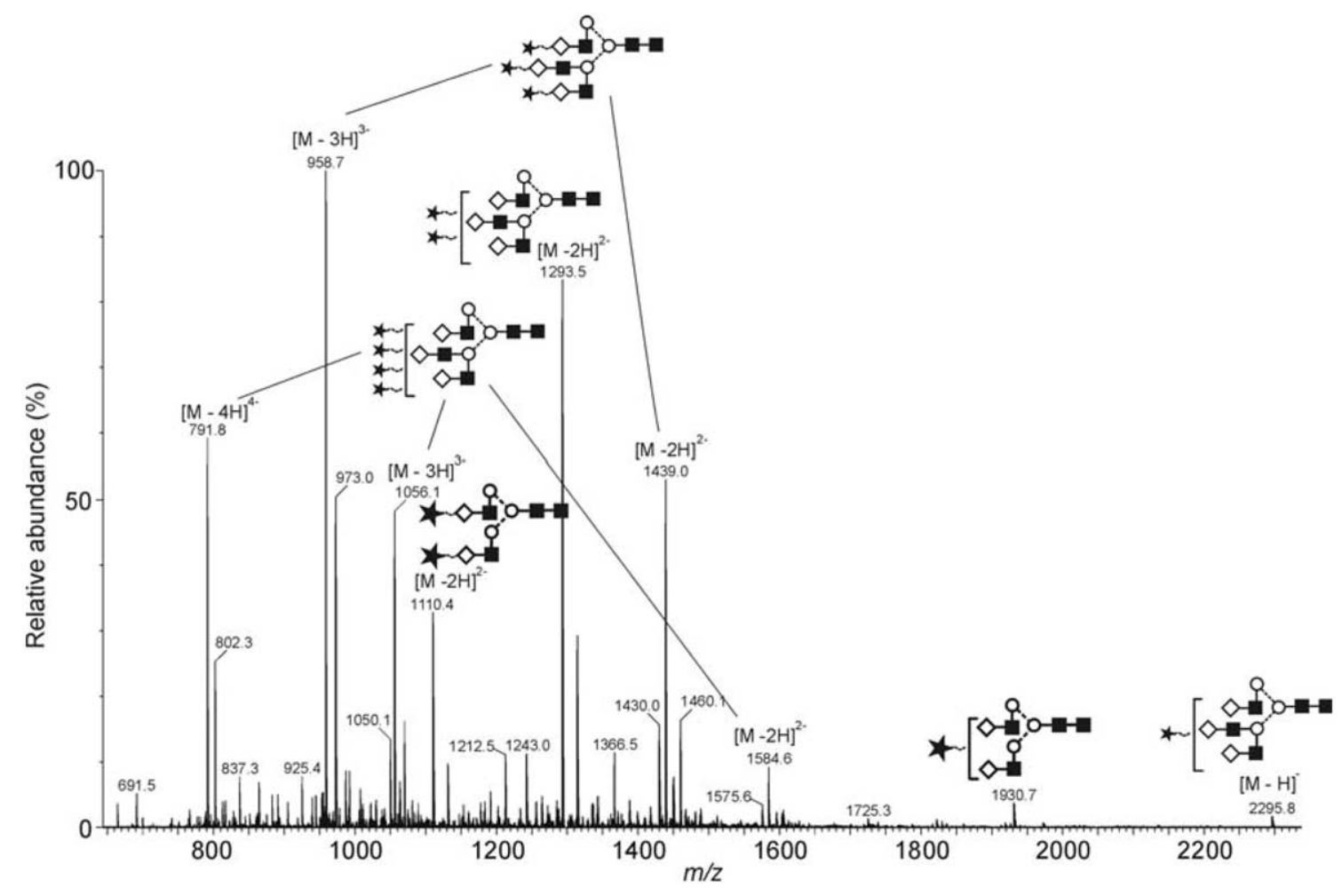

Figure 3. Negative ion mass spectrum of sialylated complex $N$-linked glycans released from bovine fetuin. Ions appearing at 42 mass units higher than those of the sialylated glycans are produced by $\mathrm{O}$-acetyl derivatives, formed as by-products of the hydrazinolysis/reacetylation method of glycan release. ${ }^{\circ}$ Symbols ${ }^{\circ}$ as $^{\circ}$ defined $^{\circ}$ in ${ }^{\circ}$ the $e^{\circ}$ legend ${ }^{\circ}$ to $^{\circ}$ Figure $^{\circ} 1^{\circ}$ plus $^{\circ}$ filled ${ }^{\circ}$ star $^{\circ}=N$-acetylneuraminic ${ }^{\circ}$ acid 


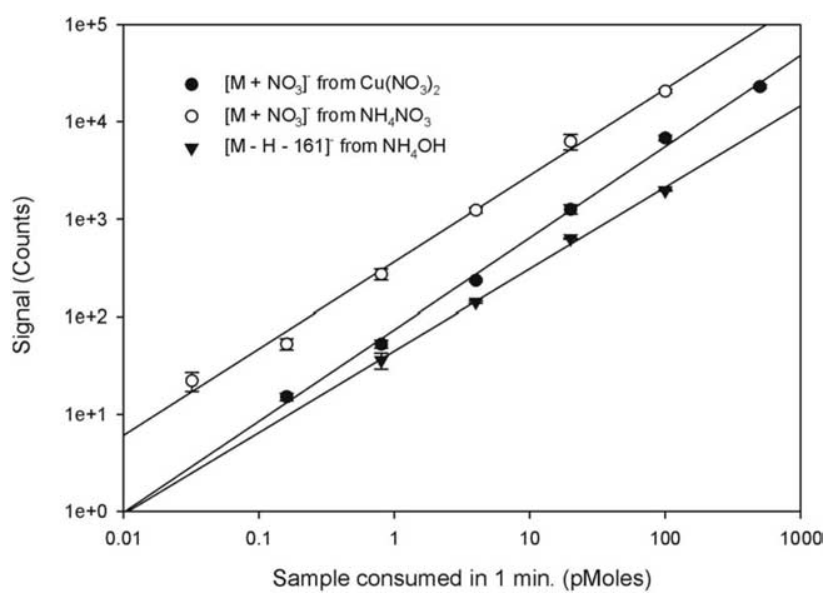

Figure 4. Plot of signal strength against sample consumption for the $[\mathrm{M}-\mathrm{H}]^{-}$and $\left[\mathrm{M}+\mathrm{NO}_{3}\right]^{-}$ions from the high-mannose $\mathrm{N}$-linked glycan (Man $)_{5}(\mathrm{GlcNAc})_{2}$.

stable isotopes complicated the profiles of the molecular ions. However, none of the fragment ions contained halogen from either of these adducts.

As observed earlier for $N$-linked glycans and other

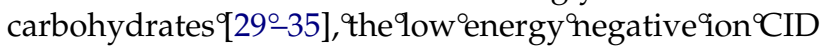
spectra contained mainly ions produced by $\mathrm{C}$-type and

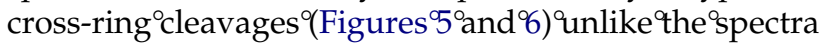
of positive ions such as $[\mathrm{M}+\mathrm{Na}]^{+}$that gave mainly Band Y-ions. This observation can be rationalized, as detailed in the following paper, by proton abstraction from various hydroxyl groups to leave an electrondense center that readily fed electrons into the sugar rings, causing them to cleave. The spectrum shown in Figure $^{\circ} 5^{\circ}$ contained $^{\circ}$ abundant $^{\circ}$ ions $^{\circ}$ at $^{\circ} \mathrm{m} / z \quad 1072.5^{\circ}$ and 869.4 produced by ${ }^{2,4} \mathrm{~A}$ cross ring cleavages of the GlcNAc residues of the chitobiose core. The masses of these ions was unchanged in the spectrum of the corresponding glycan containing a fucose residue at C-6 of the reducing terminal GlcNAc residue, allowing this common substitution to be easily identified. In contrast to the positive ion spectra, fucose tended not to be lost in the negative ion spectra and, consequently, its substitution position could often be determined by appropriate mass shifts in the diagnostic ions. An ${ }^{\mathrm{O}, 2} \mathrm{~A}_{4}$ cleavage of the penultimate GlcNAc residue was also observed $^{\circ}\left(\mathrm{m} / \mathrm{z}\right.$ 929.4, ${ }^{\circ}$ Figure $\left.^{\circ} 5\right) . .^{\circ}$ The $^{\circ}$ prominent $^{\circ}{ }^{\mathrm{O}, 3} \mathrm{~A}_{3}$ cleavage of the branching core mannose residue $\left(\mathrm{m} / \mathrm{z} \quad 575.3,{ }^{\circ} \text { Figure }^{\circ} 5\right)^{\circ}$ conveniently $^{\circ}$ isolated ${ }^{\circ}$ the ${ }^{\circ} 6$-antenna, thus allowing its composition to be determined. An ion produced by a similar cleavage was present in the positive ion spectra of the sodium adduct but at a very much lower relative abundance.

Cleavages occurring in these negative ion spectra were much more specific than in the positive ion spectra such that "internal fragments" (fragments produced by cleavages at multiple sites) were less common with the result that many of the fragment ions were more diagnostic of structural features of the glycans than in the positive ion spectra. For example, the ion

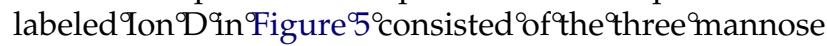
residues from the 6-antenna together with the branching mannose of the core and, again provided specific information on the composition of the 6-antenna. A similar ion was present in the positive ion spectra but appeared to be ${ }^{\circ}$ ormed by $^{\circ}$ several routes [56], \%eading to ambiguity in several spectra. Under high energy positive ion conditions, this ion eliminated a GlcNAc molecule ( $221 \mathrm{u})$ when a bisecting GlcNAc $(1 \rightarrow 4$ linked to the core branching mannose residue) was present but this fragmentation was usually insignificant in the low energy spectra of the type produced by the Q-TOF instrument. In the negative ion mode, however, this diagnostic cleavage was very prominent and produced

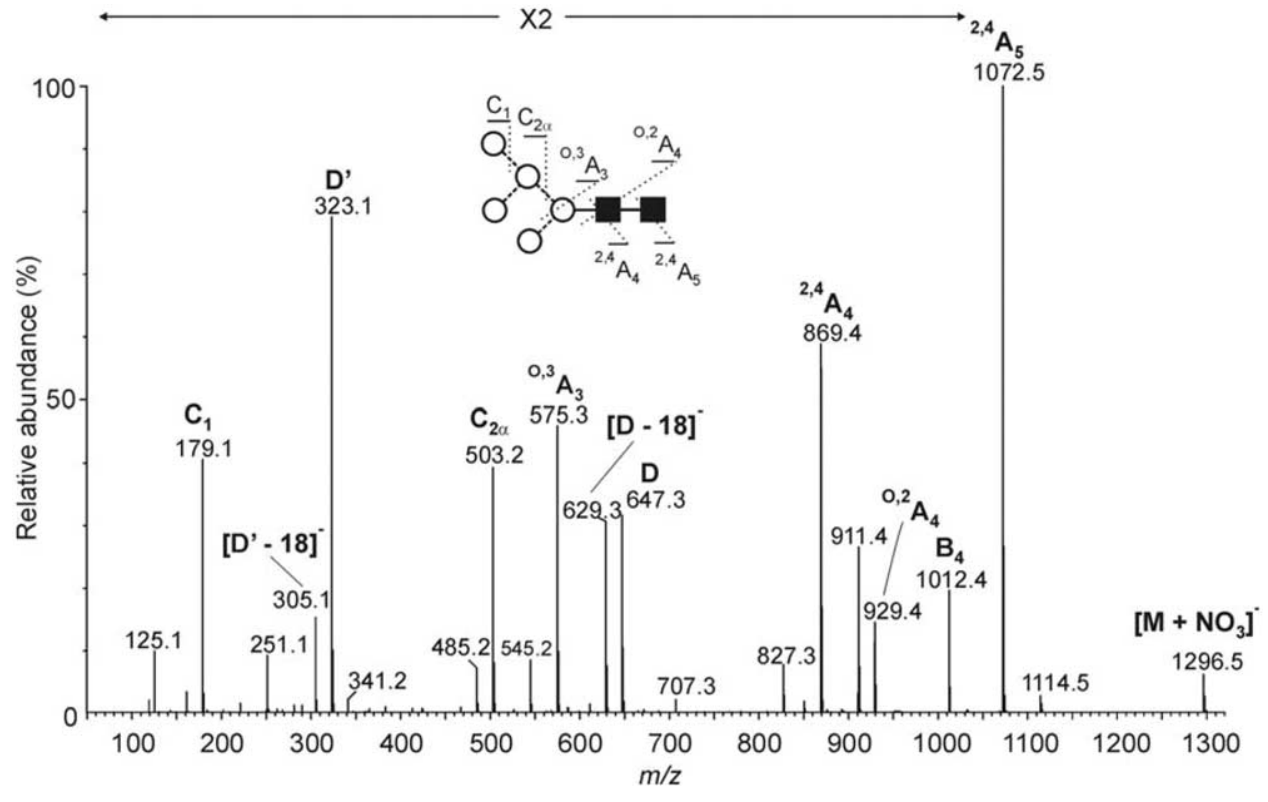

Figure 5. CID spectrum of the $\left[\mathrm{M}+\mathrm{NO}_{3}\right]^{-}$ion from $(\mathrm{Man})_{5}(\mathrm{GlcNAc})_{2}$. 


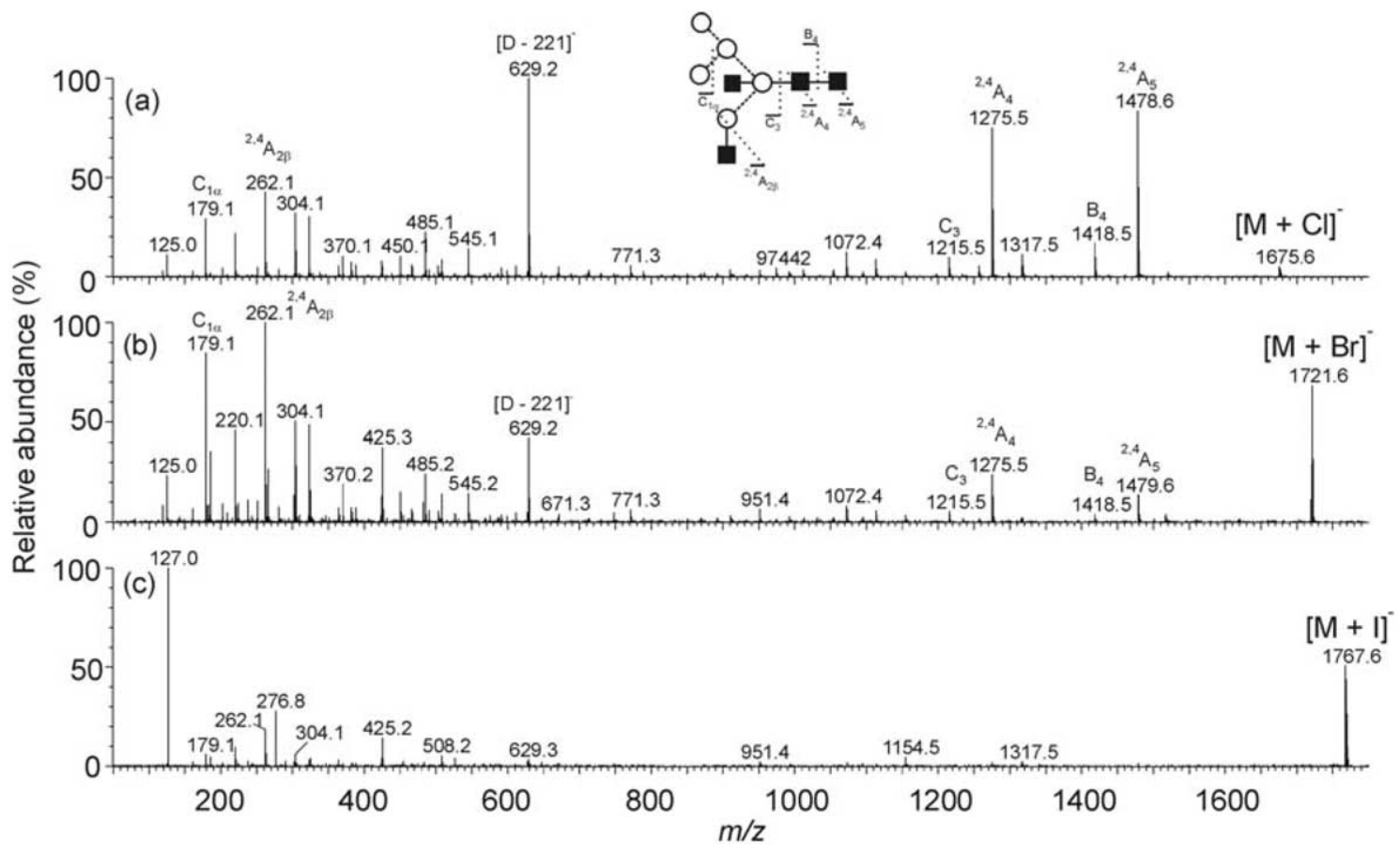

Figure 6. Negative ion CID spectra of (a) the $\left[\mathrm{M}+\mathrm{Cl}^{-}\right.$, (b) the $[\mathrm{M}+\mathrm{Br}]^{-}$, and (c) the $\left[\mathrm{M}+\mathrm{I}^{-}\right.$ions from the hybrid $\mathrm{N}$-linked glycan (Man) $)_{5}(\mathrm{GlcNAc})_{4}$.

the most abundant ion in the spectrum as discussed in a following paper. Additional ions in the spectrum of the ${ }^{\circ}$ compound $^{\circ}$ whose $^{\circ}$ spectrum $^{\circ}$ is ${ }^{\circ}$ shown $^{\circ}$ in ${ }^{\circ}$ Figure $^{\circ} 5$ reflected the structure of the 6-antenna. The substitution pattern of the 6-antenna is similar to that of the core branching mannose (3,6-substitution) and, consequently ions equivalent to Ion $\mathrm{D}$ (labeled $\mathrm{D}^{\prime}$ ) and its accompanying $\left[\mathrm{D}^{\prime}-\mathrm{H}_{2} \mathrm{O}\right]^{-}$were present $(\mathrm{m} / \mathrm{z} 323.1$ and 305.1, respectively).

The doubly-charged ions from the neutral glycans produced spectra containing mainly singly-charged fragments that were very similar to those from the corresponding singly-charged ions. Because these ions were formed more efficiently than singly-charged ions from the larger glycans, this property provided the best opportunity for obtaining fragmentation spectra from these larger compounds. Spectra of the multiplycharged ions from the acidic glycans, on the other hand, were less informative as they were dominated by multiply-charged fragments and fragments containing the sialic acid as the result of the preferential loss of the acidic, rather than the hydroxylic protons.

\section{Conclusions}

Nitrate adducts of the type $\left[\mathrm{M}+\mathrm{NO}_{3}\right]^{-}$formed from ammonium nitrate gave stable complexes with the released $N$-linked glycans when examined by electrospray allowing them to be detected with about ten times the sensitivity of the $[\mathrm{M}-\mathrm{H}]^{-}$ions. They prevented the formation of the abundant in-source fragments that were a feature of the $[\mathrm{M}-\mathrm{H}]^{-}$ions. CID fragmentation gave predominantly C-type glycosidic and A-type cross-ring cleavages that were formed by more specific and, consequently, more diagnostic processes than the $\mathrm{B}$ and $\mathrm{Y}$ ions that dominated the positive ion spectra. Ions were found that revealed information on the presence or absence of a fucose residue in the reducingterminal GlcNAc residue and the presence of a bisecting GlcNAc residue. Some ions were also specific to the individual antenna, allowing their compositions to be determined. Many of these structural features are unavailable or difficult to obtain from positive ion spectra or from classical experiments involving exoglycosidase digestions.

\section{Acknowledgments}

The author thanks Professor R. A. Dwek, Director of the Glycobiology Institute, for his help and encouragement and also the Wellcome Trust for an equipment grant to purchase the Q-TOF mass spectrometer.

\section{References}

1. Varki, A. Biological roles of oligosaccharides: All of the theories are correct. Glycobiology 1993, 3, 97-130.

2. Dwek, R. A. Glycobiology: Towards understanding the function of sugars. Chem. Rev. 1996, 96, 683-720.

3. Dwek, R. A.; Edge, C. J.; Harvey, D. J.; Wormald, M. R.; Parekh, R. B. Analysis of glycoprotein-associated oligosaccharides. Ann. Rev. Biochem. 1993, 62, 65-100.

4. Rudd, P. M.; Dwek, R. A. Rapid, sensitive sequencing of oligosaccharides from glycoproteins. Curr. Opin. Biotechnol. 1997, 8, 488-497. 
5. Rudd, P. M.; Guile, G. R.; Küster, B.; Harvey, D. J.; Opdenakker, G.; Dwek, R. A. Oligosaccharide sequencing technology. Nature 1997, 388, 205-207.

6. Rudd, P. M.; Colominas, C.; Royle, L.; Murphy, N.; Hart, E.; Merry, A. H.; Hebestreit, H. F.; Dwek, R. A. A high-performance liquid chromatography based strategy for rapid, sensitive sequencing of $\mathrm{N}$-linked oligosaccharide modifications to proteins in sodium dodecyl sulphate polyacrylamide electrophoresis gel bands. Proteomics 2001, 1, 285-294.

7. Sutton, C. W.; O'Neill, J. A.; Cottrell, J. S. Site-specific characterization of glycoprotein carbohydrates by exoglycosidase digestion and laser desorption mass spectrometry. Anal. Biochem. 1994, 218, 34-46.

8. Harvey, D. J.; Rudd, P. M.; Bateman, R. H.; Bordoli, R. S.; Howes, K.; Hoyes, J. B.; Vickers, R. G. Examination of complex oligosaccharides by matrix-assisted laser desorption/ionization mass spectrometry on time-of-flight and magnetic sector instruments. Org. Mass Spectrom. 1994, 29, 753-765.

9. Royle, L.; Mattu, T. S.; Hart, E.; Langridge, J. I.; Merry, A. H.; Murphy, N.; Harvey, D. J.; Dwek, R. A.; Rudd, P. M. An analytical and structural database provides a strategy for sequencing O-glycans from microgram quantities of glycoproteins. Anal. Biochem. 2002, 304, 70-90.

10. Dell, A. FAB Mass spectrometry of carbohydrates. Adv. Carbohydrate Chem. Biochem. 1987, 45, 19-72.

11. Dell, A.; Carman, N. H.; Tiller, P. R.; Thomas-Oates, J. E. Fast atom bombardment mass spectrometric strategies for characterizing carbohydrate-containing biopolymers. Biomed. Environ. Mass Spectrom. 1987, 16, 19-24.

12. Dell, A.; Thomas-Oates, J. E., Fast atom bombardment-mass spectrometry (FAB-MS): Sample preparation and analytical strategies, In Analysis of Carbohydrates by GLC and MS; Biermann, C. J.; McGinnis, G. D., Eds.; CRC Press: Boca Raton, 1989; pp 217-235.

13. Dell, A.; Morris, H. R. Glycoprotein structure determination by mass spectrometry. Science 2001, 291, 2351-2356.

14. Mock, K. K.; Davy, M.; Cottrell, J. S. The analysis of underivatized oligosaccharides by matrix-assisted laser desorption mass spectrometry. Biochem. Biophys. Res. Commun. 1991, 177, 644-651.

15. Stahl, B.; Steup, M.; Karas, M.; Hillenkamp, F. Analysis of neutral oligosaccharides by matrix-assisted laser desorption/ ionization mass spectrometry. Anal. Chem. 1991, 63, 1463-1466.

16. Harvey, D. J. Matrix-assisted laser desorption/ionization mass spectrometry of carbohydrates. Mass Spectrom. Rev. 1999, 18, 349-451.

17. Orlando, R.; Bush, C. A.; Fenselau, C. Structural analysis of oligosaccharides by tandem mass spectrometry: Collisional activation of sodium adduct ions. Biomed. Environ. Mass Spectrom. 1990, 19, 747-754.

18. Spengler, B.; Kirsch, D.; Kaufmann, R.; Lemoine, J. Structure analysis of branched oligosaccharides using post-source decay in matrix-assisted laser desorption/ionization mass spectrometry. J. Mass Spectrom. 1995, 30, 782-787.

19. Shevchenko, A.; Loboda, A.; Shevchenko, A.; Ens, W.; Standing, K. G. MALDI Quadrupole time-of-flight mass spectrometry: A powerful tool for proteomic research. Anal. Chem. 2000, 72, 2132-2141.

20. Verhaert, P.; Uttenweiler-Joseph, S.; de Vries, M.; Loboda, A.; Ens, W.; Standing, K. G. Matrix-assisted laser desorption/ ionization quadrupole time-of-flight mass spectrometry: An elegant tool for peptidomics. Proteomics 2001, 1, 118-131.

21. Loboda, A. V.; Krutchinsky, A. N.; Bromirski, M.; Ens, W.; Standing, K. G. A quadrupole/time-of-flight mass spectrometer with a matrix-assisted laser desorption/ionization source: design and performance. Rapid Commun. Mass Spectrom. 2000, 14, 1047-1057.
22. Harvey, D. J.; Bateman, R. H.; Bordoli, R. S.; Tyldesley, R. Ionization and fragmentation of complex glycans with a Q-TOF mass spectrometer fitted with a MALDI ion source. Rapid Commun. Mass Spectrom. 2000, 14, 2135-2142.

23. Harvey, D. J. Collision-induced fragmentation of underivatized $\mathrm{N}$-linked carbohydrates ionized by electrospray. J. Mass Spectrom. 2000, 35, 1178-1190.

24. Reinhold, V. N.; Reinhold, B. B.; Costello, C. E. Carbohydrate molecular weight profiling, sequence, linkage and branching data: ES-MS and CID. Anal. Chem. 1995, 67, 1772-1784.

25. Harvey, D. J.; Bateman, R. H.; Green, M. R. High-energy collision-induced fragmentation of complex oligosaccharides ionized by matrix-assisted laser desorption/ionization mass spectrometry. J. Mass Spectrom. 1997, 32, 167-187.

26. Harvey, D. J. N-[2-diethylamino]ethyl-4-aminobenzamide derivatives for high sensitivity mass spectrometric detection and structure determination of $\mathrm{N}$-linked carbohydrates. Rapid Commun. Mass Spectrom. 2000, 14, 862-871.

27. Harvey, D. J. Electrospray mass spectrometry and collisioninduced fragmentation of 2-aminobenzamide-labeled neutral N-linked glycans. Analyst 2000, 125, 609-617.

28. Harvey, D. J. Electrospray mass spectrometry and fragmentation of N-linked carbohydrates derivatized at the reducing terminus. J. Am. Soc. Mass Spectrom. 2000, 11, 900-915.

29. Chai, W.; Piskarev, V.; Lawson, A. M. Negative-ion electrospray mass spectrometry of neutral underivatized oligosaccharides. Anal. Chem. 2001, 73, 651-657.

30. Pfenninger, A.; Karas, M.; Finke, B.; Stahl, B. Structural analysis of underivatized neutral human milk oligosaccharides in the negative ion mode by nano-electrospray MS $^{\mathrm{n}}$ (Part 1: Methodology). J. Am. Soc. Mass Spectrom. 2002, 13, 1331-1340.

31. Pfenninger, A.; Karas, M.; Finke, B.; Stahl, B. Structural analysis of underivatized neutral human milk oligosaccharides in the negative ion mode by nano-electrospray $\mathrm{MS}^{\mathrm{n}}$ (Part 2: Application to isomeric mixtures). J. Am. Soc. Mass Spectrom. 2002, 13, 1341-1348.

32. Chai, W.; Piskarev, V.; Lawson, A. M. Branching pattern and sequence analysis of underivatized oligosaccharides by combined MS/MS of singly and doubly charged molecular ions in negative-ion electrospray mass spectrometry. J. Am. Soc. Mass Spectrom. 2002, 13, 670-679.

33. Quéméner, B.; Désiré, C.; Lahaye, M.; Debrauwer, L.; Negroni, L. Structural characterization of both positive- and negative-ion electrospray mass spectrometry of partially methyl-esterified oligogalacturonides purified by semi-preparative high-performance anion-exchange chromatography. Eur. J. Mass. Spectrom. 2003, 9, 45-60

34. Sagi, D.; Peter-Katalinic, J.; Conradt, H. S.; Nimtz, M. Sequencing of tri- and tetra-antennary $\mathrm{N}$-glycans containing sialic acid by negative mode ESI QTOF tandem MS. J. Am. Soc. Mass Spectrom. 2002, 13, 1138-1148.

35. Wheeler, S. F.; Harvey, D. J. Negative ion mass spectrometry of sialylated carbohydrates: Discrimination of $\mathrm{N}$-acetylneuraminic acid linkages by matrix-assisted laser desorption/ionizationtime-of-flight and electrospray-time-of-flight mass spectrometry. Anal. Chem. 2000, 72, 5027-5039.

36. Domon, B.; Costello, C. E. A systematic nomenclature for carbohydrate fragmentations in FAB-MS/MS spectra of glycoconjugates. Glycoconj. J. 1988, 5, 397-409.

37. Harvey, D. J. Fragmentation of negative ions from carbohydrates: Part 2, Fragmentation of high-mannose N-linked glycans. J. Am. Soc. Mass Spectrom. 2005, 16, 631-646.

38. Harvey, D. J. Fragmentation of negative ions from carbohydrates: Part 3, Fragmentation of hybrid and complex $N$-linked glycans. J. Am. Soc. Mass Spectrom. 2005, 16, 647-659.

39. Patel, T.; Bruce, J.; Merry, A.; Bigge, C.; Wormald, M.; Jaques, A.; Parekh, R. Use of hydrazine to release in intact and 
unreduced form both $\mathrm{N}$ - and O-linked oligosaccharides from glycoproteins. Biochemistry 1993, 32, 679-693.

40. Wing, D. R.; Field, M. C.; Schmitz, B.; Thor, G.; Dwek, R. A.; Schachner, M. S.; Rademacher, T. W. The use of large-scale hydrazinolysis in the preparation of $\mathrm{N}$-linked oligosaccharide libraries: Application to brain tissue. Glycoconj. J. 1992, 9, 293-301.

41. Fu, D.; Chen, L.; O'Neill, R. A. A detailed structural characterization of ribonuclease $B$ oligosaccharides by ${ }^{1} \mathrm{H}$ NMR spectroscopy and mass spectrometry. Carbohydr. Res. 1994, 261, 173-186.

42. de Waard, P.; Koorevaar, A.; Kamerling, J. P.; Vliegenthart, J. F. G. Structure determination by ${ }^{1} \mathrm{H}$ NMR spectroscopy of (sulfated) sialylated $N$-linked carbohydrate chains released from porcine thyroglobulin by peptide- $N^{4}-(N$-acetyl- $\beta$ glucosaminyl)asparagine amidase-F. J. Biol. Chem. 1991, 266, 4237-4243.

43. Kamerling, J. P.; Rijkse, I.; Maas, A. A. M.; van Kuik, J. A.; Vliegenthart, J. F. G. Sulfated N-linked carbohydrate chains in porcine thyroglobulin. FEBS Letts. 1988, 241, 246-250.

44. Da Silva, M. L. C.; Stubbs, H. J.; Tamura, T.; Rice, K. G. ${ }^{1} \mathrm{H}-\mathrm{NMR}$ characterization of a hen ovalbumin tyrosinamide N-linked oligosaccharide library. Arch. Biochem. Biophys. 1995, 318, 465-475.

45. Harvey, D. J.; Wing, D. R.; Küster, B.; Wilson, I. B. H. Composition of N-linked carbohydrates from ovalbumin and copurified glycoproteins. J. Am. Soc. Mass Spectrom. 2000, 11, 564-571.

46. Green, E. D.; Adelt, G.; Baenziger, J. U.; Wilson, S.; van Halbeek, $\mathrm{H}$. The asparagine-linked oligosaccharides on bovine fetuin. Structural analysis of N-glycanase-released oligosaccharides by 500-Megahertz 1H-NMR spectroscopy. J. Biol. Chem. 1988, 263, 18253-18268.

47. Wong, A. W.; Cancilla, M. T.; Voss, L. R.; Lebrilla, C. B. Anion dopant for oligosaccharides in matrix-assisted laser desorp- tion/ionization mass spectrometry. Anal. Chem. 1999, 71, 205-211.

48. Wong, A. W.; Wang, H.; Lebrilla, C. B. Selection of anionic dopant for quantifying desialylation reactions with MALDIFTMS. Anal. Chem. 2000, 72, 1419-1425.

49. Cai, Y.; Concha, M. C.; Murray, J. S.; Cole, R. B. Evaluation of the role of multiple hydrogen bonding in offering stability to negative ion adducts in electrospray mass spectrometry. J. Am. Soc. Mass Spectrom. 2002, 13, 1360-1369.

50. Cole, R. B.; Zhu, J. Chloride ion attachment in negative ion electrospray ionization mass spectrometry. Rapid Commun. Mass Spectrom. 1999, 13, 607-611.

51. Zhu, J.; Cole, R. B. Formation and decomposition of chloride adduct ions, $[\mathrm{M}+\mathrm{Cl}]^{-}$, in negative ion electrospray ionization mass spectrometry. J. Am. Soc. Mass Spectrom. 2000, 11, 932941.

52. Zhu, J.; Cole, R. B. Ranking of gas-phase acidities and chloride affinities of monosaccharides and linkage specificity in collision-induced decompositions of negative ion electrospraygenerated chloride adducts of oligosaccharides. J. Am. Soc. Mass Spectrom. 2001, 12, 1193-1204.

53. Cai, Y.; Jiang, Y.; Cole, R. B. Anionic adducts of oligosaccharides by matrix-assisted laser desorption/ionization time-offlight mass spectrometry. Anal. Chem. 2003, 75, 1638-1644.

54. Hardy, M. R.; Townsend, R. R. High-pH anion exchange chromatography of glycoprotein-derived carbohydrates. Methods Enzymol. 1994, 230, 208-225.

55. Naven, T. J. P.; Harvey, D. J. Effect of structure on the signal strength of oligosaccharides in matrix-assisted laser desorption/ionization mass spectrometry on time-of-flight and magnetic sector instruments. Rapid Commun. Mass Spectrom. 1996, 10, 1361-1366.

56. Harvey, D. J.; Martin, R. L.; Jackson, K. A.; Sutton, C. W. Fragmentation of $N$-linked glycans with a MALDI-ion trap time-of-flight mass spectrometer. Rapid Commun. Mass Spectrom. 2004, 18, 2997-3007. 